\title{
A Produção Acadêmica em Ensino de Biologia no Brasil - 40 anos (1972-2011): Base Institucional e Tendências Temáticas e Metodológicas
}

\section{Research Trends in Biology Teaching from 1972 to 2011: Analysis of Dissertations and Thesis}

\author{
Paulo Marcelo Marini Teixeira ${ }^{(0)}$ Brasil \\ Jorge Megid Neto Brasil
}

O artigo analisa a produção acadêmica expressa em dissertações e teses em Ensino de Biologia, defendidas no período 1972-2011 em programas de pós-graduação existentes no Brasil. Identificamos 1000 documentos, examinados conforme os seguintes descritores: i) ano de defesa; ii) instituições de origem e distribuição geográfica; iii) titulação; iv) orientadores; v) nível escolar; vi) focos temáticos; vii) gêneros de trabalho acadêmico. Nos resultados, após explicitar detalhes sobre a base institucional sustentadora desse campo investigativo no país, algumas tendências que marcam os estudos nesta subárea relativa à Educação em Ciências são apontadas, sobretudo em relação aos níveis de ensino privilegiados, linhas temáticas e problemáticas investigadas, além de alguns elementos caracterizadores dos trabalhos examinados do ponto de vista teórico-metodológico.

Palavras-chave: Ensino de Biologia; Dissertações; Teses; Estado da Arte.

The present study is the outcome of a survey whose objective was to analyze the academic production related to dissertations and theses in Biology Teaching produced by Graduate Courses in Brazil from 1972 to 2011. The research identified 1000 documents and the analysis focused the following aspects: i) releasing year; ii) institution; iii) academic degree; iv) supervisor; v) educational level; vi) thematic focus; vii) type of academic work. As for the results, after showing details about the institutional base supporting such investigatory field in the country, some tendencies that typify the studies in this subarea of Science Education are revealed, mainly in relation to the educational levels privileged in academic works, the major thematic approaches and analyzed issues, besides some elements that characterize the studied works under a theoretical-methodological point of view.

Keywords: biology teaching; dissertations; thesis; state of the art. 


\section{Introdução}

Concentramos significativo esforço nos últimos anos no desenvolvimento de trabalhos de investigação dedicados à análise de dados sobre a pesquisa acadêmica em Ensino de Biologia, na tentativa de compreender os rumos dessa produção em nosso País. Com efeito, com a apresentação paulatina dos resultados dessas pesquisas (Teixeira, 2008; Teixeira \& Megid Neto, 2006; 2011, 2012; Teixeira \& Oliveira, 2013), revelamos informações relevantes no sentido de mapear a produção de dissertações e teses (DTs) nessa subárea relativa ao conjunto das pesquisas em Educação em Ciências (EC).

Nossa opção pelo trabalho com DTs não deveria requerer qualquer justificativa adicional, a não ser pelo fato de essa modalidade de trabalho acadêmico representar, ao longo do tempo, parte fundamental e majoritária das investigações realizadas nas instituições de ensino superior (IES). As "dissertações e teses refletem mais diretamente a produção propriamente acadêmica" (Salem, 2012, p. 22). São trabalhos vinculados a programas de pós-graduação, principais lócus de formação de pesquisadores ingressantes nas áreas de Educação e Educação em Ciências e de atuação de grupos de pesquisa engajados sistematicamente nas pesquisas das referidas áreas. "Em áreas como a educação, praticamente toda a pesquisa é desenvolvida nos programas de pós-graduação ou por sujeitos formados para a pesquisa nesses programas" (Macedo \& Sousa, 2010, p. 166). Ademais, as DTs são documentos considerados mais apropriados para pesquisas caracterizadas como estado da arte, por se tratarem de documentos primários contendo relatórios completos e mais aprofundados dos estudos realizados, os quais, via-de-regra, são apresentados posteriormente de maneira sucinta em artigos publicados em livros, periódicos ou eventos (Megid Neto, 1999; Salem, 2012).

Do ponto de vista histórico, em 1965, temos o momento que demarca a eclosão da pós-graduação em educação no Brasil. O primeiro programa de pós-graduação na área foi criado na PUC-RJ. Outros cursos foram criados na sequência, no período que vai do final dos anos 1960 até o início da década de 1970, configurando ponto de partida para um processo de expansão no sistema de pós-graduação relativo à área educacional. Quando pensamos especificamente em EC, vale mencionar o ano de 1972, quando encontrarmos as primeiras dissertações e teses defendidas nessa área específica, entre as quais, estão as três primeiras enquadradas dentro da subárea de Ensino de Biologia: i) Ieda Costa Marchiori, "Uma nova perspectiva da Biologia Educacional no currículo dos cursos de formação de professores primários" (Mestrado, Centro de Educação, UFSM); ii) Maria de Lourdes Mercier Medina, "A atitude cibernética aplicada ao ensino de Biologia" (Mestrado, Centro de Teologia e Ciências Humanas, PUC-RJ); iii) Myriam Krasilchik, "O ensino de Biologia em São Paulo: fases de renovação" (Doutorado, Faculdade de Educação, USP) (Teixeira, 2008; Megid Neto, 2014).

Portanto, em 2015, atingimos cinco décadas de desenvolvimento de estudos e pesquisas associadas aos cursos de pós-graduação vinculados ao campo da educação, incluindo os estudos em Educação em Ciências, sejam aqueles oriundos dos próprios programas de pós-graduação em educação, com linhas de pesquisa em EC; sejam aqueles 
oriundos dos programas específicos da área de EC (hoje Área de Ensino na CAPES); ou ainda também considerando a produção gestada em outros programas mais distantes da área educacional, mas que, ocasionalmente, geram trabalhos cujos objetos de pesquisa sustentam relações com aspectos do ensino e aprendizagem em ciências. Mesmo considerando as oscilações neste processo de desenvolvimento da pesquisa via pósgraduação, é inequívoco o forte desenvolvimento da área, expresso na diversidade de programas ${ }^{1}$ hoje existentes, disseminados pelas mais variadas regiões do país, gerando, em seu conjunto, recursos humanos para a educação básica e superior, uma comunidade de pesquisadores na área, além é claro, da produção de conhecimentos focalizadores de uma multiplicidade de problemáticas inerentes ao ensinar e aprender ciências.

Foi considerando essa especial ocasião $^{2}$, demarcadora, de certo modo, da maturidade institucional de nossa área, que lançamos a ideia de escrever mais um artigo voltado para a explicitação de características e tendências a marcar a pesquisa em EC no país. Em nosso caso, interessam os trabalhos acadêmicos voltados para a subárea de Ensino de Biologia ${ }^{3}$, dando continuidade ao esforço no sentido de descrever e sistematizar dados sobre a produção acadêmica e científica localizada dentro desse recorte. Entendemos que esse é um movimento imprescindível, já que à medida que a área se estruturou, a produção aumentou significativamente e se diversificou, de modo que temos a necessidade de periodicamente acompanhar os caminhos trilhados, num movimento de autorreflexão, buscando captar tendências e tradições, as mudanças, e sinalizar as perspectivas e desafios para pesquisas futuras (Goergen, 1998; Teixeira, 2008; Salem, 2012). Portanto, este trabalho faz parte de um projeto mais amplo dedicado ao mapeamento contínuo da pesquisa brasileira em Ensino de Biologia.

\footnotetext{
1 CAPES - Coordenação de Aperfeiçoamento de Pessoal de Nível Superior, fundação do Ministério da Educação responsável pela aprovação, acompanhamento, avaliação e financiamento dos cursos de pós-graduação no país. Em pesquisa realizada na Plataforma Sucupira - Cursos Recomendados (CAPES), sobre os programas hoje existentes, detectamos, para dados relativos até 2016, 157 programas cadastrados na área de Ensino e 177 na área de Educação. Fonte: https://sucupira.capes.gov.br. Acesso: março 2017.

2 Considerando o início da pós-graduação em Educação no país em 1965, completamos, em 2015, cinco décadas de pós-graduação na referida área.

3 Interessaram à investigação as DTs que, de alguma forma, apresentam referências ao ensino e aprendizagem de conteúdos vinculados às Ciências Biológicas. Com efeito, o ambiente escolar investigado, os sujeitos envolvidos na pesquisa (professores, formadores, estudantes, licenciandos, estagiários etc.), os cursos de formação inicial e/ou continuada, os materiais e recursos didáticos analisados, os métodos e técnicas de ensino testados, os programas de ensino propostos, a avaliação dos currículos nos seus diversos níveis e possibilidades, a legislação, as experiências educacionais relatadas nos estudos realizados, enfim, um ou mais desses elementos presentes em cada trabalho devem ter relação direta ou, pelo menos, parcial com o Ensino de Biologia (Teixeira, 2008).
} 
O objetivo deste artigo é identificar, descrever e analisar a produção envolvendo o Ensino de Biologia, expressa sob a forma de DTs defendidas entre 1972 até 2011, contemplando 40 anos de estudos acadêmicos desenvolvidos na referida subárea. Com efeito, apresentamos resultados consolidados considerando a finalização da fase principal da investigação, explicitando dados complementares e atualizando informações divulgadas em trabalhos anteriormente publicados. ${ }^{4}$. Desta forma, questões importantes a responder são as seguintes: Como se desenvolve, quantitativa e qualitativamente, a produção acadêmica em Ensino de Biologia ao longo do tempo? Qual é a base institucional sustentadora dessa produção acadêmica? Temos programas de pós-graduação, orientadores e grupos consolidados na produção de conhecimento e na formação de pesquisadores nessa área? Quais as temáticas e tendências de investigação polarizam a atenção dos pesquisadores? Quais os principais níveis de ensino focalizados nas pesquisas? Existem lacunas a exigir o desenvolvimento de novas pesquisas?

\section{Aspectos Metodológicos}

O período de abrangência da pesquisa começa em 1972, ano em que, segundo nossos registros, os primeiros trabalhos em Ensino de Biologia foram defendidos no país. O marco final é 2011, data estabelecida para finalizar a coleta de dados junto aos bancos de informação sobre dissertações e teses. Em nosso caso, além da busca em dados do "Banco de Teses - BT/CAPES", principal fonte para a pesquisa que toma como objeto de estudo as DTs, também consultamos as páginas da internet dos programas de pósgraduação cadastrados nas áreas de Educação e Ensino da CAPES e visitamos também as bibliotecas on-line de IES onde esses programas estão instalados. Foram visitados 128 sites de programas de pós-graduação, entre os quais, 59 ligados à área de Educação e 34 à área de Ensino (Ensino de Ciências e Matemática), além de visitas às bibliotecas on line de todas as 89 instituições identificadas no processo de busca. Adicionalmente, para completar a coleta de dados, visitamos a Plataforma Lattes - CNPq, buscando examinar os currículos de potenciais orientadores vinculados ao Ensino de Biologia. Para isso, utilizamos como base para consulta uma lista contendo 232 nomes de pessoas que formaram a Comissão Científica para trabalhos submetidos ao V Encontro Nacional de Ensino de Biologia (ENEBIO), realizado na USP em setembro de $2014^{6}$.

Esses procedimentos, adotados para a busca de dados sobre as DTs em Ensino de Biologia (palavras-chave ${ }^{7}$, títulos, referências e resumos), vem sendo aprimorados ao longo do tempo. Aprendemos, com as experiências acumuladas em pesquisas

\footnotetext{
4 Um artigo com dados preliminares dessa pesquisa foi publicado no ENPEC-2013, em Águas de Lindóia, sob o título "40 anos de pesquisa em Ensino de Biologia no Brasil: um estudo baseado em dissertações e teses (19722011)". Confere em Teixeira e Oliveira (2013).

5 Banco de Teses da CAPES: http://www.capes.gov.br/servicos/banco-de-teses.

6 Informações sobre essa Comissão Avaliadora podem ser encontradas no endereço eletrônico da Associação Brasileira de Ensino de Biologia. Recuperado de http://www.sbenbio.org.br/

7 Palavras-chave empregadas de forma combinada no processo de busca: Biologia; Ciências Biológicas; Ensino; Aprendizagem; Educação; Ensino de Biologia; Ciência; Ensino de Ciências; Educação em Ciências; Educação Científica; Alfabetização Científica.
} 
anteriores, que o Banco de Teses da CAPES é atualizado de forma irregular, de modo que muitos trabalhos acabam sendo cadastrados com atraso ou simplesmente não aparecem nos registros da CAPES. Assim, este processo de triangulação de fontes para coleta de informações úteis para a identificação do escopo de cada trabalho, garante que parte significativa das DTs em Ensino de Biologia produzidas no Brasil, no período sob investigação, sejam "capturadas", embora não possamos garantir que todas as DTs defendidas nesses 40 anos estejam retratadas no conjunto de documentos constituído para dar base para a pesquisa. No quadro atual, diante da magnitude da expansão da área, a recuperação, análise e catalogação da produção acadêmica em Ensino de Ciências nos estudos do tipo Estado da Arte está se tornando, cada vez mais, um processo difícil e complexo, devido ao elevado número de DTs defendidas a cada ano e a necessidade de consultar diversas bases de informação para a coleta de dados (Megid Neto, 2014).

Ao final do processo de busca, encerrado em meados de 2015, os resultados obtidos permitiram a totalização de exatas 1000 referências. Prosseguimos as buscas posteriormente e localizamos novos trabalhos, ainda circunscritos ao período estipulado para esta investigação, que serão examinados em fase posterior da pesquisa. A partir da identificação das DTs, seus resumos e referências institucionais/bibliográficas foram organizados em fichas e tabelas de análise.

Examinando esse material com uma abordagem de natureza quanti-qualitativa, desenvolvemos a análise preliminar dos documentos, estabelecendo a classificação das DTs conforme os seguintes descritores: a) ano de defesa e evolução quantitativa da produção acadêmica; b) instituições onde os trabalhos foram desenvolvidos e distribuição geográfica; c) titulação; d) orientadores; e) nível escolar privilegiado nos estudos acadêmicos; f) linhas e focos temáticos; g) gêneros de trabalho acadêmico.

A primeira etapa da análise envolveu a organização dos dados em planilhas, tabelas e gráficos, procurando facilitar a análise de tendências emergentes do conjunto de documentos arrolados durante a investigação. As referências gerais para cada trabalho ajudaram a compor o que chamamos de "base institucional": conjunto de informações que nos permite examinar a dinâmica de produção pelas diversas instituições brasileiras, seu desenvolvimento diacrônico, suas características institucionais, etc. Isso foi feito com ajuda de alguns dos descritores supramencionados (descritores a, b, c, d). Por sua vez, os resumos já permitiam um processo de imersão inicial sobre o conteúdo das DTs, com a identificação de temáticas, problemáticas, nível de escolarização privilegiados nos estudos acadêmicos, modalidades de pesquisa etc. (descritores e, f, g). Neste caso, os originais dos trabalhos disponíveis somente foram consultados quando os resumos e referências institucionais/bibliográficas não permitiram a obtenção das informações desejadas para esta etapa. Por isso, grande parte das DTs (90\%) foi obtida por meio eletrônico ou impresso, para uma análise mais aprofundada envolvendo o conteúdo integral de cada trabalho.

A apresentação dos resultados é aqui dividida em duas seções. A primeira está centrada sobre o que chamamos de "base institucional" e, a segunda, focalizada nos 
problemas de pesquisa e tendências temáticas e metodológicas que caracterizam a produção acadêmica em Ensino de Biologia nos 40 anos examinados neste artigo.

\section{Resultados, Análises e Reflexões}

\section{Base Institucional}

A análise da produção de DTs de Ensino de Biologia nos 40 anos examinados pela pesquisa, revela um quadro de expansão e diversificação que tem se intensificado significativamente nos últimos anos. A evolução anual da produção identificada (1000 documentos) pode ser visualizada na Figura 1. A primeira característica a salientar é o crescimento em termos quantitativos, evidenciando que desde o aparecimento dos primeiros trabalhos, em princípios dos anos 1970, a pesquisa com foco no Ensino de Biologia expandiu-se, com crescimento modesto e irregular, até meados da década de 1990. Considerando todo o período, esse movimento expansivo acontece em sintonia com o desenvolvimento da área de EC e com a pesquisa educacional tomada em sentido mais amplo, como indicam os trabalhos de Teixeira e Megid Neto (2006; 2011; 2012), Macedo e Sousa (2010), Salem (2012), Teixeira (2012) e Megid Neto (2014). Tal crescimento está associado a processos verificados nos últimos 25 anos de expansão e diversificação da pós-graduação e de formação e consolidação da pesquisa educacional no país. Como se observa no gráfico, houve pequeno crescimento até 1997, com algumas flutuações. Porém, na parte final dos anos 1990, verificamos um aumento vigoroso no número de defesas. É importante destacar que, nos últimos 15 anos, o número de trabalhos defendidos aumentou expressivamente: $77,2 \%$ das defesas detectadas entre 1972 e 2011 ocorreram nos últimos 10 anos.

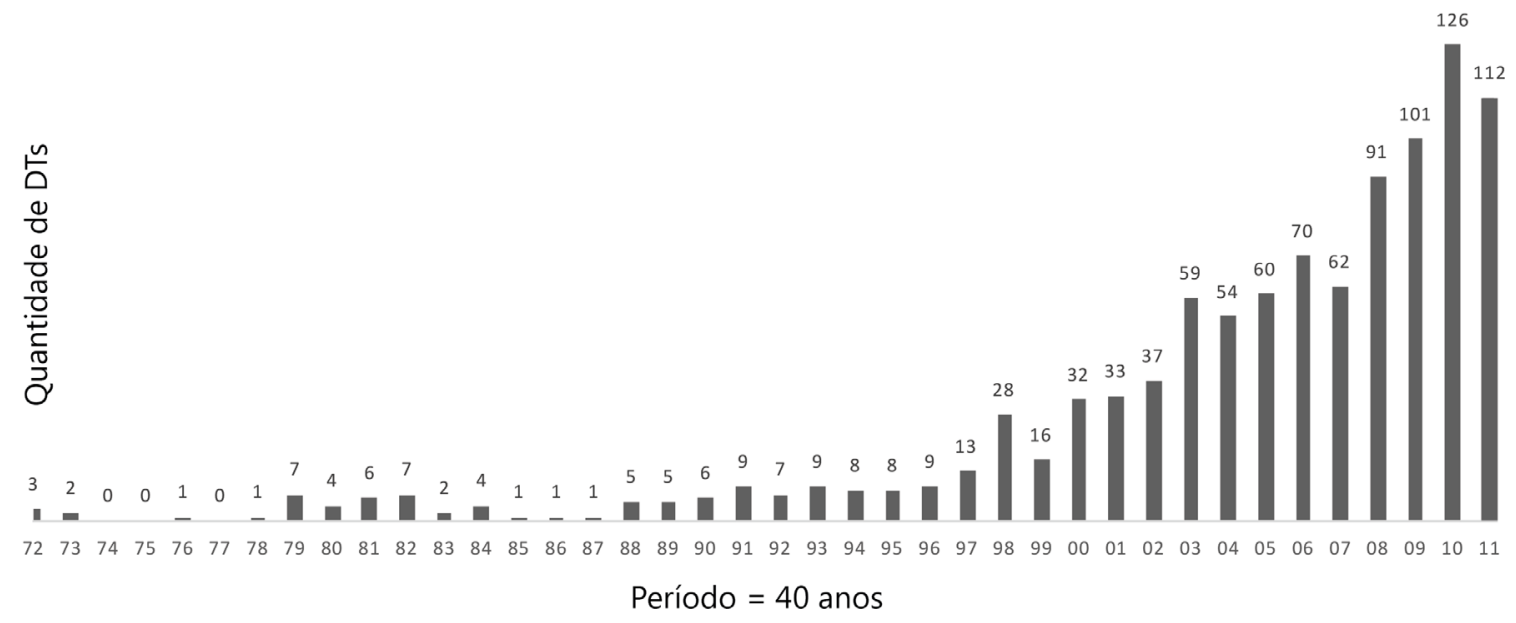

Figura 1: Gráfico da distribuição diacrônica das 1000 DTs focalizando o Ensino de Biologia defendidas no período 1972-2011.

Fonte: elaborado pelos autores com base nos bancos de dados mencionados na seção de metodologia.

A distribuição da produção indica média em torno de 25 trabalhos por ano. Em 
meados dos anos 1990, a média da produção era de 8 trabalhos/ano. A partir do final dos anos noventa, período coincidente com a criação de novos programas de pós-graduação, alguns dos quais específicos para a área de EC, potencializando o desenvolvimento de pesquisas neste campo, a média anual se aproximava de 20 trabalhos anuais. Já no contexto da primeira década do século XXI, o crescimento ocorre vertiginosamente, passando, nos últimos cinco anos, para a cifra de 100 DTs a cada ano, equivalendo a crescimento de 75,7\% em relação ao quinquênio imediatamente anterior (2002-2006).

Vale observar, ainda, a distribuição de DTs em Ensino de Biologia a cada década, conforme apontam os dados da Figura 2. Nela verificamos o expressivo crescimento a cada período. Em valores aproximados temos a seguinte situação: de 1970 para 1980, taxa de crescimento em 111\%; dos anos 80 para os anos 1990, taxa de crescimento em 265\%; e, por fim, da década de 90 para os anos 2000, crescimento de 398\%. É interessante também examinar na Figura 2, a distribuição das DTs conforme as modalidades de titulação. Notamos a crescente produção de dissertações de mestrado acadêmico (M) ao longo de todo o período. As teses de doutorado (D) são raras até o final dos anos 80, com apenas seis estudos defendidos até 1990. Na década de 90 esse número é nove vezes maior que na década anterior. Já durante os anos 2000, ultrapassa a marca de uma centena. De todo modo, as teses de doutorado correspondem a algo próximo a $16 \%$ da produção analisada. As dissertações de mestrado profissional (MP) aparecem somente nos últimos seis anos ${ }^{8}$, perfazendo 99 trabalhos até 2011. Considerando-se todo o período, totalizam quase $10 \%$ dos trabalhos identificados. Porém, se focalizarmos os últimos seis anos apurados, já que a primeira dissertação de MP aparece somente em 2006, poderíamos dizer que esse percentual atinge $17,6 \%$, indicando tendência de aumento da produção nessa modalidade de pós-graduação.

Parece que o MP vai impulsionar a área daqui para frente, dado o aumento significativo do número de programas dentro dessa modalidade. $\mathrm{Na}$ esteira desse processo, na área de Ensino (CAPES), até maio de 2016 encontrávamos 162 cursos de pós-graduação: 58 cursos de mestrado acadêmico, 31 de doutorado e 73 de mestrado profissional. Com efeito, atualmente a maioria dos cursos da referida área é constituída de MP (45\%). Na área de Educação, que até o início da década de 2010 não admitia a presença dos cursos de MP, encontramos ${ }^{9}$, por meio da consulta realizada no site da CAPES, 42 (17\%) cursos de mestrado profissional, 128 de mestrado acadêmico e 74 cursos de doutorado.

8 Os mestrados profissionais foram instituídos no país em 1995, via Portaria Capes n. 47, regulamentada pela Portaria n. 80/1998, na qual o Ministério da Educação "chama para si a responsabilidade relacionada à regulamentação e à oferta desses cursos. A proposta de flexibilização do modelo de Pós-Graduação Stricto Sensu em nível de mestrado (acadêmico e profissional) foi pautada na necessidade de uma formação universitária que atendesse as demandas sociais, considerando que as mudanças tecnológicas e as correntes de transformações econômico-sociais necessitam de profissionais com perfis de especialização distintos" dos tradicionalmente existentes até aquele momento (Chisté, 2016, p. 790).

9 Dados obtidos em visita à página da CAPES. Recuperado de http://www.capes.gov.br/cursos-recomendados. Acesso: maio 2016. 


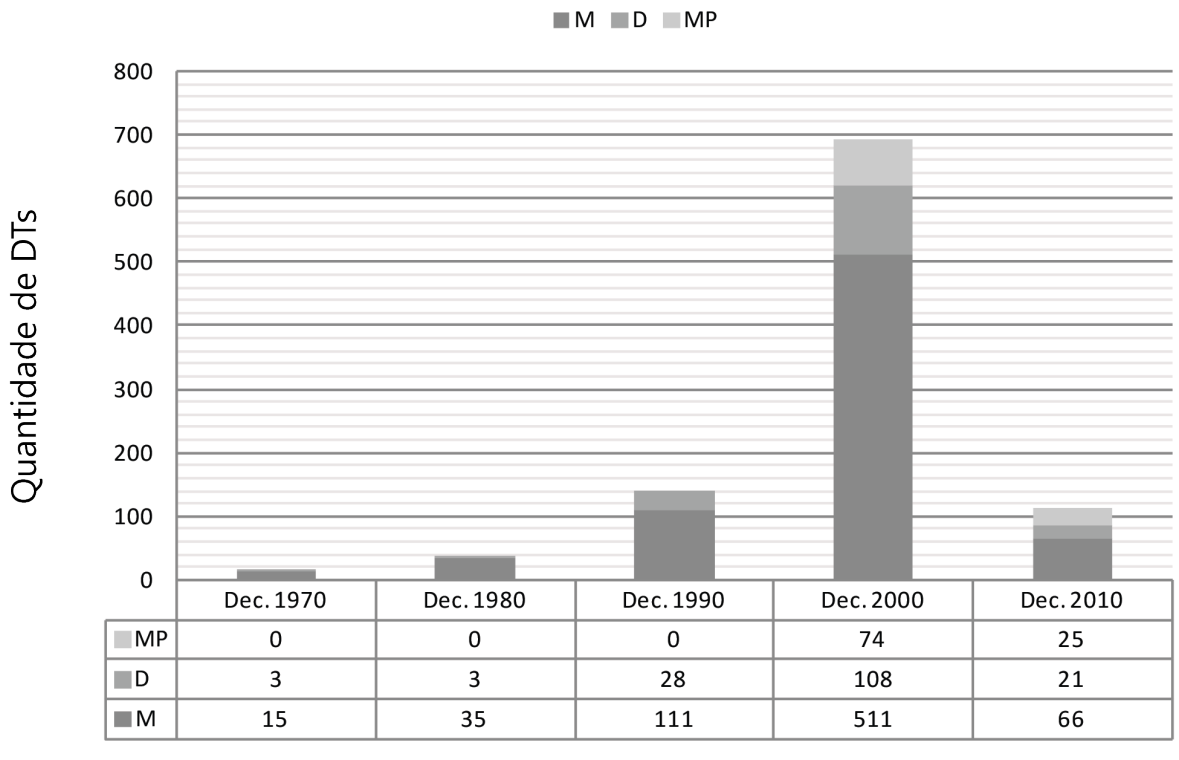

Décadas

Figura 2. Distribuição das DTs em Ensino de Biologia no Brasil (1972-2011) por décadas, considerando também o descritor titulação.

Legenda: M: Mestrado Acadêmico; D: Doutorado; MP: Mestrado Profissional. Fonte: elaborado pelos autores.

Interessante será acompanhar os reflexos desse movimento nos próximos anos, assim como o impacto dos trabalhos realizados nesses cursos em termos de geração de conhecimento e de formação docente. Há poucas informações sobre os MP, tanto para o campo de pesquisa, quanto para a qualidade da formação de professores e dos processos de ensino e aprendizagem na área. Daí a necessidade de realizarmos estudos mais aprofundados a esse respeito, na tentativa de acumularmos dados empíricos para abastecer as reflexões sobre esse fenômeno dentro da área educacional (expansão dos MP) e, em particular, na área de EC. A nosso juízo, faltam estudos de levantamento voltados para analisar características e tendências das dissertações e outros trabalhos produzidos dentro dos MP. Vale também refletir sobre as demandas que atingem atualmente a pós-graduação nas áreas de Educação e Ensino na CAPES. É certo que a formação de professores para o ensino superior e a capacitação de técnicos atuantes na gestão governamental para questões educacionais foram metas previstas para a pósgraduação (Megid Neto, 1999; Macedo \& Sousa, 2010); depois passamos a valorizar com mais intensidade a formação de pesquisadores e a produção de conhecimento. Nos últimos tempos estamos diante de um modelo que mescla essas prioridades, assumindo a pesquisa e a produção de conhecimentos educacionais de modo articulado ou integrado à formação de professores e demais profissionais da educação.

Quanto à distribuição geográfica, permanece a forte concentração nas regiões Sul e Sudeste. Elas perfazem conjuntamente 78,5\% das DTs examinadas. O Sudeste aglutina 
a maior parte dos trabalhos, totalizando 54,7\%. Encontramos trabalhos em 22 unidades federativas, incluindo o Distrito Federal. Entretanto, em estados como Tocantins, Acre e Maranhão não identificamos DTs em Ensino de Biologia. Outros como Alagoas, Espírito Santo, Mato Grosso do Sul, Sergipe, Piauí, Rondônia e Paraíba possuem produção muito pequena e ocasional. Os estados em que a produção é, numericamente, mais significativa são: São Paulo: 338 trabalhos; Rio de Janeiro: 126; Rio Grande do Sul: 96; Minas Gerais: 82; Santa Catarina: 72; Paraná: 70; Pernambuco: 41; Bahia: 41. A tabela apresentada na sequência ilustra a distribuição das 1000 DTs em Ensino de Biologia em percentuais pelas regiões brasileiras.

Tabela 1. Distribuição da produção de Dissertações e Teses em Ensino de Biologia por região brasileira (1972-2011)

\begin{tabular}{lcc}
\hline Região & Quantidade de Dissertações/Teses & \% \\
\hline Norte & 29 & 2,9 \\
Centro-Oeste & 66 & 6,6 \\
Nordeste & 120 & 12,0 \\
Sul & 238 & 23,8 \\
Sudeste & 547 & 54,7 \\
Total & 1000 & 100,0 \\
\hline
\end{tabular}

Fonte: elaborado pelos autores.

A centralização da produção acadêmica no eixo Sul-Sudeste é tendência também detectada para todo o conjunto das pesquisas educacionais, caracterizando situação que reflete a desigualdade na distribuição do conjunto de programas de pós-graduação nas diferentes áreas, bem como reflete a própria desigualdade social e econômica entre as várias regiões brasileiras. Segundo o $\mathrm{CNPq}$, por motivos relacionados a própria história do país, as regiões Norte, Nordeste e Centro-Oeste sofrem defasagem em termos de número de pesquisadores e no desenvolvimento da pós-graduação das universidades locais em relação às demais do país. Estudos como os apresentados por Gatti (1983), Campos e Fávero (1994), Lüdke (2006), em levantamentos diversos a respeito da situação da pesquisa educacional brasileira, salientam que uma das características históricas da produção de pesquisas em educação é, justamente, sua distribuição desigual no território brasileiro, acompanhando a desigualdade do desenvolvimento econômico entre as várias regiões. $\mathrm{Na}$ área de $\mathrm{EC}$ essa situação se mantém, conforme mostram trabalhos de Megid Neto (1999), Lemgruber (1999), Teixeira (2008), Salem (2012) e Megid Neto (2014). Entretanto, a comparação desses dados com aqueles apresentados anteriormente em nossas pesquisas, permite-nos encontrar discretas modificações (Teixeira, 2008; 2012; Teixeira \& Oliveira, 2013). A próxima figura dá uma ideia desse movimento em perspectiva diacrônica.

Nota-se, na Figura 3, que o eixo Sul-Sudeste concentrava $85 \%$ da produção até 2004; atualmente concentra algo em torno de 78\%. A produção na região Sul tem ficado estável, em torno dos 23\%. Em relação às regiões Nordeste, Centro-Oeste e Norte, 
temos um quadro de aumento paulatino de sua representatividade. Essas regiões juntas perfaziam $15 \%$ das DTs até 2004; passaram a $17,1 \%$ até 2006 ; e agora chegam a $21,5 \%$ (até 2011). Nossa hipótese para explicar essa dinâmica é que estamos assistindo a um moderado movimento de descentralização da pesquisa na área, reflexo de políticas públicas dos últimos anos, voltadas para a criação de IES nas regiões supracitadas e também para diminuição das assimetrias entre diversas regiões brasileiras no que diz respeito ao financiamento para pesquisas e geração de programas de mestrado e doutorado nas instituições do Norte, Nordeste e Centro-Oeste. Com efeito, isso vem contribuindo para aumentar a representatividade dessas regiões no campo das pesquisas em Ensino de Biologia, com destaque para as IES de Pernambuco e da Bahia, além de outros programas criados na Amazônia, Pará e Ceará.

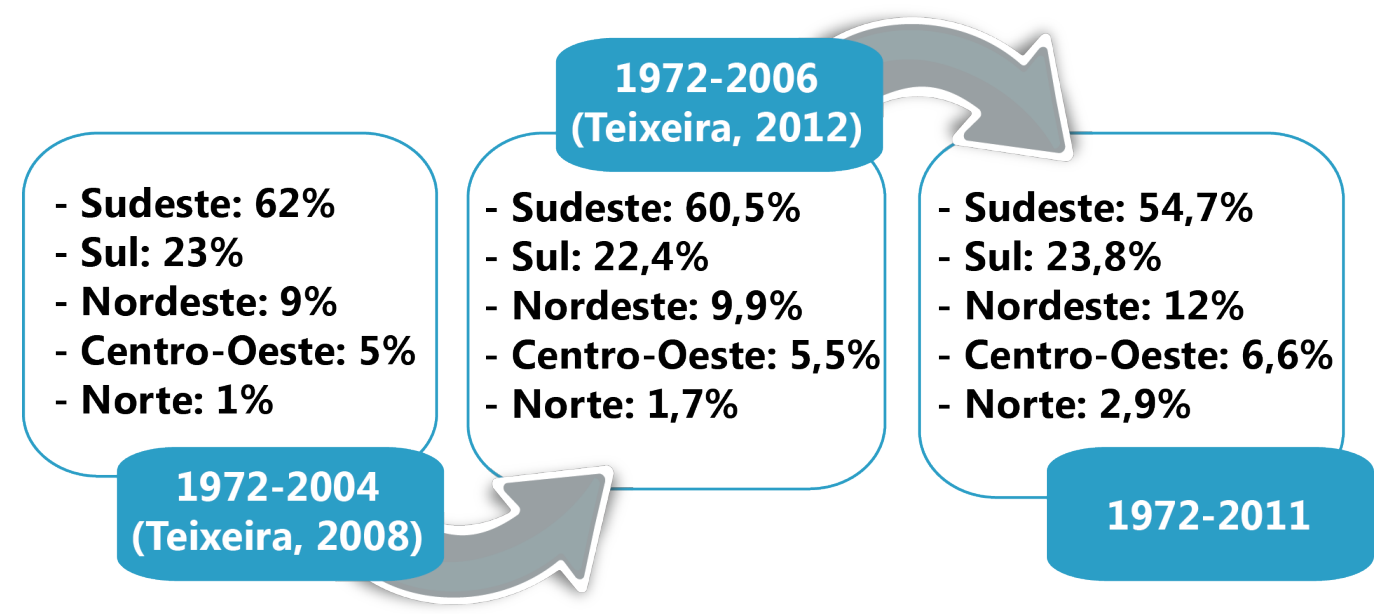

Figura 3. Dinâmica de distribuição regional das DTs em três diferentes momentos caracterizados por trabalhos relativos ao mapeamento da produção acadêmica na subárea de Ensino de Biologia.

Fonte: elaborado pelos autores.

Detectamos trabalhos em 89 diferentes IES. A produção se desenvolve predominantemente nas instituições públicas: são 788 defesas, sendo que 304 se referem às instituições estaduais, 476 a federais e, por fim, oito trabalhos relativos a apenas uma instituição municipa ${ }^{10}$. Dentre as IES estaduais há predomínio das localizadas em São Paulo, concentrando 236 trabalhos em relação à totalidade dos 1000 documentos (USP: 102; UNESP: 82; UNICAMP: 52). Dentre as IES federais, se destacam a UFSC (58), a UFRJ (42), a UFBA (36), a FIOCRUZ-RJ (34) e a UFRPE (28). Assim, os trabalhos defendidos em instituições públicas equivalem a $79 \%$ da produção total; os $21 \%$ restantes comparecem em universidades privadas (212 documentos), destacando-se as IES do sistema PUC, a exemplo da PUC-MG, PUC-RS e PUC-SP. Os dados quantitativos relativos à distribuição das DTs por natureza institucional são ilustrados na Figura 4.

10 Trata-se da FURB - Fundação Universidade Regional de Blumenau, estado de Santa Catarina. 


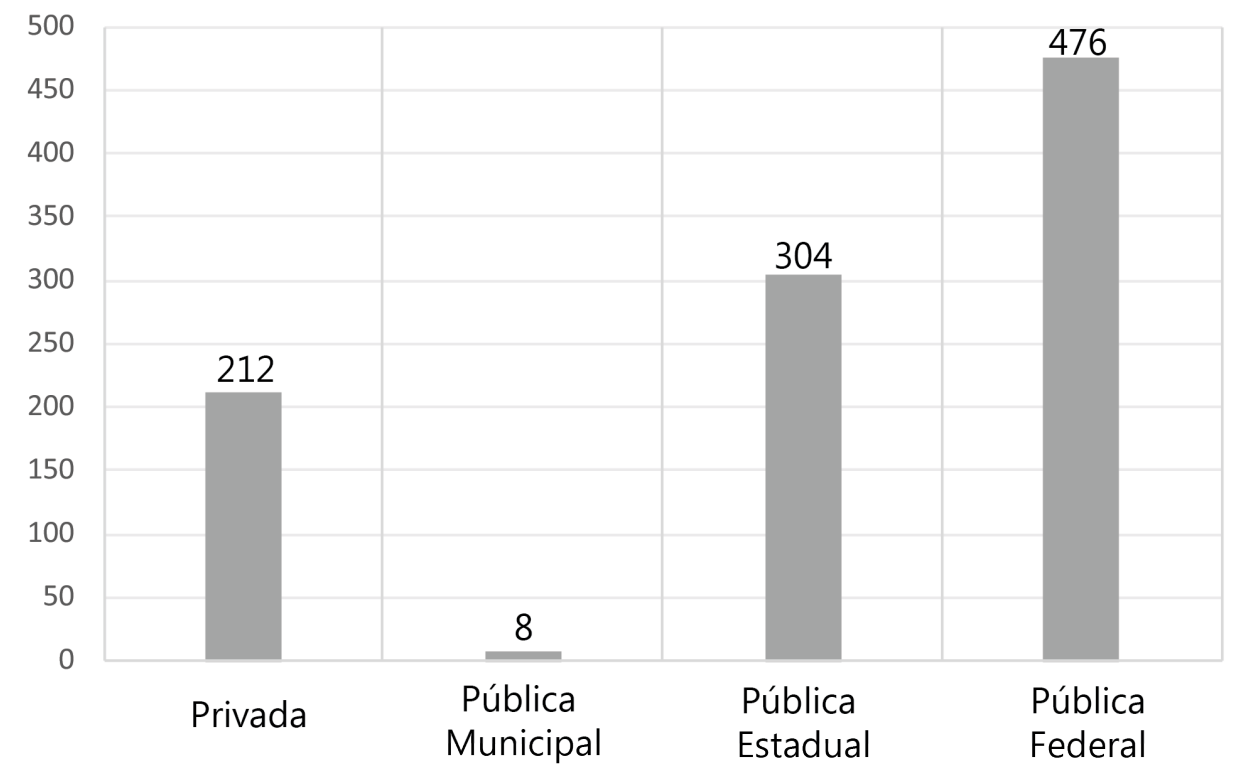

Figura 4. Gráfico da distribuição das DTs em Ensino de Biologia segundo a natureza institucional (1972-2011).

Fonte: elaborado pelos autores.

Considerando os dados disponíveis na série histórica examinada, é inevitável constatar que as instituições públicas continuam a constituir o ambiente privilegiado para formação de recursos humanos e produção de conhecimento no setor aqui analisado.

Quanto às áreas de conhecimento dos programas de pós-graduação responsáveis pela produção das DTs aqui analisadas, temos as seguintes informações. Os programas específicos de EC se converteram nos polos concentradores de estudos na subárea estudada, sendo responsáveis por 443 documentos (44,3\%). Esta é, sem dúvida, uma tendência emergente, já que, há pouco tempo, as DTs em Ensino de Biologia tinham nos programas da área de Educação seus principais lócus de produção. De fato, institutos, faculdades e centros de educação exerceram e ainda exercem relevante papel na produção de trabalhos em Ensino de Biologia, concentrando 41,2\% (412 documentos) de toda a produção detectada até 2011. Como já explicitamos em publicações anteriores (Teixeira \& Megid Neto, 2011; 2012) o papel dos centros de educação é destacado pelos próprios pesquisadores no processo histórico de formação da área de EC, posto que apoiaram a formação de mestres e doutores, inclusive quando pensamos nos primeiros pesquisadores militantes na área, que, "impossibilitados de se capacitarem nos institutos de origem, por supostas incoerências de objetos de estudo, recorreram e ainda recorrem às faculdades de Educação para cursar seus mestrados e/ou doutorados sobre o ensino das Ciências" (Nardi, 2007, p. 373).

Os programas localizados na área de Ciências Biológicas contabilizam 44 DTs $(4,4 \%)$. Além disso, encontramos trabalhos em diversas outras áreas, como, por 
exemplo: Engenharia de Produção, Letras/Linguística, Química Biológica/Bioquímica, Biotecnologia, Educação Tecnológica, Ciências da Saúde e Saúde Pública, Psicologia, Sexologia, Ciências Ambientais, Educação Matemática, Ciências da Religião, etc.

Um detalhe sobre a diversificação da pós-graduação mencionada anteriormente tem relação com as inúmeras modalidades de programas geradores de trabalhos em Ensino de Biologia. Se antes era imperioso mencionar as áreas de Educação e Ensino de Ciências e Matemática, atualmente temos uma área de Ensino, localizada na grande área Multidisciplinar da CAPES, além da própria área de Educação, que comportam, em conjunto, também programas de educação tecnológica, educação ambiental, educação em saúde, ensino na Educação Básica, todos estes, potenciais geradores de novos trabalhos na subárea de Ensino de Biologia.

Uma pergunta, formulada no início do trabalho, pode ter sua resposta agora esboçada: temos programas de pós-graduação, orientadores e grupos consolidados na produção de conhecimento e na formação de pesquisadores nessa subárea?

Para tentar responder a essas questões, cruzamos os dados sobre os orientadores comasinformaçõessobreasprincipais IES produtoras detrabalhos. Emtermosnuméricos, os principais centros produtores de DTs em Ensino de Biologia são os seguintes: USP (102 documentos); UNESP (82); UFSC (58); UNICAMP (52); UFRJ (42); PUC-MG (39); UFBA (36); FIOCRUZ-RJ (34); PUC-RS (31); UnB (31). Todavia, é preciso olhar para estes dados com cuidado, pois, para parte das instituições citadas, temos vários campi, unidades e programas de pós-graduação. Assim, quando mencionamos a USP, o ponto de destaque é a Faculdade de Educação, mas também temos alguns trabalhos oriundos do Instituto de Biociências e de outras unidades. Quando falamos em UNESP, papel de destaque deve ser atribuído ao Programa de Educação para a Ciência, localizado no campus de Bauru/SP. Quando citamos a UFSC, vale mencionar o papel do Centro de Educação e, posteriormente, o Programa em Educação Científica e Tecnológica. Já para a UNICAMP, temos trabalhos produzidos na Faculdade de Educação e no Instituto de Biologia. Sem dúvida, estes quatro casos, junto com as outras instituições listadas acima, constituem os principais núcleos e/ou grupos produtores de DTs na subárea sob investigação, tanto do ponto de vista quantitativo, como também, quando pensamos na história de implantação das pesquisas e na formação de pesquisadores que hoje constituem quadros fundamentais relativos a essa subárea.

Percebemos, nas informações obtidas sobre os orientadores, a sinalização para algum nível de dispersão ou isolamento, em função da grande quantidade de orientadores vinculados a um, dois ou três trabalhos ( $\cong 90 \%$ dos orientadores), muitos dos quais distribuídos em grandes intervalos de tempo. Porém, isso não significa a ausência de nomes de referência para a área. Identificamos a presença de pesquisadores que, desde os anos 1970, estão vinculados à pesquisa em Ensino de Biologia. Outros defenderam seus trabalhos de doutorado nos anos 1980-90, passando a atuar como orientadores e exercendo, a partir de então, fundamental papel na consolidação de programas de pós-graduação e linhas de pesquisa, como também para a formação de 
novos pesquisadores que passaram a integrar essa subárea (Teixeira \& Megid Neto, 2012). Há também orientadores com 5, 6 e até mais orientações concluídas, que podem estar em processo de consolidação de seu trabalho e grupos de pesquisa. Na próxima tabela temos orientadores vinculados a pelo menos uma dezena de DTs defendidas no período examinado na pesquisa.

Tabela 2. Principais orientadores de Dissertações e Teses em Ensino de Biologia, em termos quantitativos, no período de 1972 a 2011

\begin{tabular}{llc}
\hline Orientadores & Instituição & Quantidade \\
\hline Charbel Niño El-Hani & IB-UFBA & 18 \\
Myriam Krasilchik & FEUSP & 15 \\
Silvia L. F. Trivelato & FEUSP & 15 \\
Nelio M. V. Bizzo & FEUSP & 14 \\
Ana Maria A. Caldeira & UNESP-BRU & 12 \\
Maria Helena S. Carneiro & UnB & 12 \\
Regina Maria R. Borges & PUC-RS & 12 \\
Luzia Marta Bellini & UEM & 11 \\
Sandra L. Escovedo Selles & FE-UFF & 11 \\
\hline Total & - & $\mathbf{1 2 0}$ \\
\hline
\end{tabular}

Fonte: elaborado pelos autores.

Considerando os 40 anos de produção acadêmica em Ensino de Biologia, ao examinar a tabela, parece haver um pequeno número de orientadores fortemente vinculados à subárea. Porém, essa afirmação tem que ser analisada com cuidado. A nosso ver, isso não é um problema, já que não podemos esquecer que a área de EC é interdisciplinar e multifacetada. Boa parte de nossos pesquisadores tomam objetos de pesquisa mais amplos do que o escopo específico referente ao Ensino de Biologia, envolvendo questões como a Formação de Professores, História e Filosofia da Ciência, Currículo, Ensino-Aprendizagem etc. De qualquer forma, o grande número de sujeitos que denotam que a orientação de trabalhos na subárea de Ensino de Biologia é pontual não deixa de ser um dado preocupante. De fato, quando examinamos a área de EC em sentido mais amplo, focalizando a relação dos pesquisadores (orientadores) com suas respectivas linhas de pesquisa, por vezes nos deparamos com informações indicadoras da falta de coerência e dispersão de linhas, programas de pesquisa e referenciais teóricometodológicos (Barros, 2002; Moreira, 2004; Salem, 2012). Certamente, este é um aspecto que os pesquisadores, os programas de pós-graduação e a Área, como um todo, deveriam avaliar, procurando estratégias para minimizar esse problema.

Em síntese, o quadro encontrado para a análise de instituições e orientadores reitera o argumento formulado por Megid Neto (2007), ao analisar a presença de instituições de tradição em pesquisa e sinalizar para a existência de "centros já consolidados e de ampla produção de pesquisa na área, convivendo com instituições cuja produção pequena e ocasional - não denota a existência de grupos de pesquisa consolidados ou com interesse regular na área" (p. 346). 


\section{Tendências Temáticas e Metodológicas que Caracterizam a Produção Acadêmica em Ensino de Biologia}

\section{Contexto de Aplicação dos Estudos Acadêmicos: níveis de ensino}

Quanto ao contexto de desenvolvimento dos trabalhos analisados no período 1972-2011, isto é, as faixas de escolarização focalizadas pelos pesquisadores nos estudos em Ensino de Biologia, gostaríamos de salientar a concentração de trabalhos dedicados ao Ensino Médio e à Educação Superior ao longo do tempo. Considerando todo o período, praticamente $70 \%$ das DTs se referem a estudos centrados nesses dois níveis de ensino. A tabela fixada na sequência traz mais informações relativas à distribuição dos trabalhos segundo o descritor "nível de ensino".

Tabela 3. Distribuição por décadas das 1000 DTs em Ensino de Biologia conforme nível de ensino investigado (1972-2011).

\begin{tabular}{lcccccccccc}
\hline Nível de Ensino & EI & EF & EM & EF/EM & ES & EF/ES & EM/ES & G & O+NI & EJA \\
\hline $1972-1980$ & 0 & 1 & 7 & 0 & 9 & 1 & 0 & 0 & 0 & 0 \\
$1981-1990$ & 0 & 7 & 8 & 3 & 16 & 0 & 1 & 2 & 1 & 0 \\
$1991-2000$ & 0 & 25 & 37 & 18 & 40 & 0 & 6 & 11 & 2 & 0 \\
$2001-2010$ & 3 & 99 & 245 & 43 & 203 & 4 & 37 & 42 & 2 & 15 \\
2011 & 1 & 15 & 42 & 5 & 36 & 1 & 5 & 4 & 0 & 3 \\
\hline Totais & 4 & 147 & 339 & 69 & 304 & 6 & 49 & 59 & 5 & 18 \\
\hline
\end{tabular}

Siglas: EI: Educação Infantil; EF: Ensino Fundamental; EM: Ensino Médio; ES: Educação Superior; G: Geral;

O+NI: Outro + Nível Não-Identificado; EJA: Educação de Jovens e Adultos. Fonte: elaborado pelos autores.

Em relação a trabalhos associados ao Ensino Médio (EM), foram encontrados 339 (33,9\%) documentos abordando isoladamente esse nível escolar e 457 quando associamos a essa cifra inicial os estudos tratando do Ensino Médio em conjunto com outros níveis (EF/EM; EM/ES). Isso significa que um percentual em torno de $45 \%$ dos trabalhos vincula-se ao contexto da escola de ensino médio, onde a disciplina escolar Biologia se faz presente tradicionalmente nos currículos escolares do país (Krasilchik, 1986; Selles \& Ferreira, 2005). Além disso, o ensino médio é lócus principal de atuação dos formados em Ciências Biológicas, parte dos quais, acaba investindo esforços no aprimoramento de sua formação acadêmica e professoral através de cursos de mestrado (acadêmico e profissional) e doutorado. A produção dedicada a esse nível de ensino se intensificou na década de 1990, recebendo forte incremento dadas as relações do Ensino de Biologia com temáticas ligadas ao avanço das Ciências Biológicas, particularmente quando pensamos nas biotecnologias, questões ambientais e discussões sobre educação em saúde, Biologia Evolutiva, questões éticas (bioéticas), além de outras vinculadas à tríade Ciência, Tecnologia, Sociedade (CTS), atraindo pesquisadores interessados no impacto dessas questões no contexto das aulas.

No que concerne à Educação Superior, os trabalhos voltados para problemáticas especificamente ligadas a esse segmento de ensino perfazem 304 documentos $(30,4 \%)$. 
Quando adicionamos a esse número, os documentos que tratam da Educação Superior em conjunto com outros níveis (EF/ES; EM/S), temos 359 DTs, ou seja, aproximadamente $36 \%$ dos trabalhos examinados nesta investigação. Consideramos que o significativo número de estudos focalizando o nível superior de ensino ocorre em função de, pelo menos, duas situações. O desenvolvimento inicial da pós-graduação no país é uma delas, já que esteve ligado à expansão das vagas na universidade, aos investimentos na formação dos quadros docentes das IES e às exigências de titulação acadêmica para ingresso ou ascensão na carreira do magistério superior (Megid Neto, 1999; Kuenzer \& Moraes, 2005). Daí a tendência dos pós-graduandos da época (décadas de 1970 e 1980), em focalizar as investigações nos aspectos relacionados à Educação Superior, posto que eram poucos os mestrandos e doutorandos a acumular experiências e contato com a escola básica (Teixeira, 2008). Devemos notar que, ao observar a Tabela 3, o nível de ensino que concentra a maior quantidade de trabalhos nas décadas de 1970 e 1980 é justamente a Educação Superior. A segunda situação está ligada às temáticas de estudo predominantes ao longo dos 40 anos abarcados pelo presente estudo. Há intenso interesse nas questões relacionadas à formação de professores e à análise de aspectos associados aos cursos de formação (currículos, licenciandos, egressos, estágio, prática de ensino etc.), problemáticas de investigação fortemente ligadas à Educação Superior.

Outra característica que se mantém no decurso do tempo é a quantidade menor de trabalhos dedicados ao Ensino Fundamental (EF) que, em seu conjunto, totalizam $22 \%$ das DTs. Tal fenômeno pode ser explicado, posto que, nesse nível de ensino, a Biologia está diluída nos conteúdos de Ciências Naturais (Krasilchik, 2004; Scarpa \& Silva, 2013). Examinando os dados, encontramos apenas 19 trabalhos que tomam como objeto de estudo problemáticas relativas aos anos iniciais do Ensino Fundamental $\left(1^{\circ}-5^{\circ}\right.$ ano). Os estudos que analisam problemáticas relativas ao Ensino Fundamental tendem a focalizar, preferencialmente, os anos finais dessa faixa de escolarização ( $5^{\mathrm{a}}-8^{\mathrm{a}}$ séries ou, atualmente, $6^{\circ}$ ao $9^{\circ}$ ano), em que a presença dos conteúdos de Ciências Biológicas é mais intensa, sobretudo nas escolas que adotam a tradicional estrutura curricular para o ensino de Ciências, com ênfase no estudo dos 'seres vivos', 'meio ambiente' e 'corpo humano'. Assim, dos 222 trabalhos relacionados de alguma forma ao ensino fundamental, $172(77,4 \%)$ referem-se a investigações focalizando os anos finais desse segmento de escolarização.

A baixa incidência de trabalhos vinculados à Educação Infantil (apenas 4 DTs identificadas), aos anos iniciais do ensino fundamental e à Educação de Jovens e Adultos (19 DTs), em contraponto ao número de estudos dedicados ao Ensino Médio e Educação Superior, estampa uma lacuna a ser preenchida por estudos futuros, ou seja, precisamos dar mais atenção ao ensino de Biologia que acontece no contexto dos primeiros anos de escolarização de nossos estudantes. A educação infantil e os anos iniciais do ensino fundamental são de suma importância para a "futura formação científica do sujeito, na qual as crianças dão seus primeiros passos na educação científica escolar" (Megid Neto, 2014, p. 122). Analogamente, é preciso lembrar que, muitas vezes, o contexto da 
Educação de Jovens e Adultos (EJA) representa o único espaço de inserção de jovens e adultos na cultura científica. Assim, é urgente reverter essa reduzida atenção que está sendo dispensada a essas faixas de escolarização.

\section{Linhas de Investigação a Polarizar a Atenção dos Pesquisadores}

Para o estudo deste item adotamos estratégia relativamente diferente em relação a trabalhos que publicamos anteriormente sobre a produção acadêmica em Ensino de Biologia. Neste artigo, numa tentativa de abarcar mais adequadamente a diversidade de linhas temáticas a envolver os estudos da área de EC, procuramos fundir os descritores para focos temáticos utilizados até então (Megid Neto, 1999; Teixeira, 2008; Teixeira \& Megid Neto, 2012), com as linhas temáticas propostas em um dos eventos mais importantes da área, o Encontro Nacional de Pesquisa em Educação em Ciências (ENPEC) em sua décima edição ${ }^{11}$. Com efeito, o resultado dessa fusão foi um conjunto de categorias preliminares (linhas temáticas), ainda em construção, sujeitas a ajustes e adequações, mas que são úteis no sentido de compreendermos a diversidade de linhas de investigação que nossa área tem produzido nos últimos anos. Como consequência deste processo de hibridização de categorias, o número de focos temáticos subiu de 11 para 17, de tal sorte que, com isso, embora possamos ter zonas de sobreposição e redundância entre certas categorias, assim como uma maior pulverização na classificação para as linhas temáticas, ganhamos em abrangência e na capacidade de percepção da pluralidade de problemáticas de pesquisa que caracteriza a área de EC, e de Ensino de Biologia em particular nas últimas décadas. Na sequência, apresentamos cada uma delas, para, em seguida, trazer os resultados da análise realizada.

1. Ensino e Aprendizagem (E-A): analisam aspectos cognitivos, sociais e afetivos envolvidos no ensino
e aprendizagem de conceitos científicos em diferentes faixas de ensino; ambientes de aprendizagem;
aprendizagem colaborativa; modelos e modelagem na Educação em Ciências/Biologia; ensino
por investigação e/ou experimentação. Análise de dinâmicas para trabalhos em grupo (exemplos:
rodas de conversa, debates, rodas de ciência, dramatização etc.), sequências didáticas, unidades
de ensino, atividades práticas etc. Parte dos estudos descrevem como determinados conteúdos são
ministrados nas aulas; examinam também a relação conteúdo-método, com foco nos processos de
ensino-aprendizagem a envolver o conhecimento científico veiculado na escola e a forma como
este conhecimento é difundido por meio de métodos e estratégias de ensino. Descrição e análise
a respeito da aplicação de métodos e estratégias no ensino, como instrução programada, módulos
personalizados de ensino, courseware, dramatização, unidades didáticas, entre outros, de forma
isolada ou comparativa. Trabalhos que propõem métodos alternativos ou que descrevem e avaliam
práticas pedagógicas e as metodologias de ensino nelas empregadas.

Figura 4. Descrição dos focos temáticos utilizados na classificação das 1000 Dissertações e Teses em Ensino de Biologia (1972-2000) (continua)

11 Os descritores utilizados anteriormente foram os seguintes: Currículos e Programas; Formação de Professores; Conteúdo-Método; Recursos Didáticos; Formação de Conceitos; Características do Professor; Características do Aluno; Organização da Escola; Educação Não-Formal; História e Filosofia da Ciência; Outros focos. Para encontrar as linhas temáticas utilizadas no X ENPEC consulte o endereço eletrônico: http://www.xenpec.com.br/ pt/texto.php?id_texto=2. 
2. Formação de Professores (FP): preocupam-se com a formação inicial de professores para o ensino na área, no âmbito da Licenciatura em Ciências Biológicas ou correlatas, da Pedagogia ou do curso Normal de Ensino Médio. Estudos de avaliação ou propostas de reformulação de cursos de formação inicial de professores. Estudos voltados para a formação continuada, permanente e formação no exercício da docência de professores de Ciências Biológicas, envolvendo propostas e/ou avaliação de programas de aperfeiçoamento, atualização, capacitação, treinamento ou especialização de professores. Descrição e avaliação da prática pedagógica e outros aspectos de interesse nos processos de formação inicial e continuada. Análise de programas e políticas de formação inicial e formação continuada; avaliação de modelos e práticas de formação de professores para diferentes níveis e modalidades de ensino. Estudos sobre a formação e o desenvolvimento profissional de professores e/ou das relações entre pesquisa e formação de professores.

3. Características dos Professores (CP): examinam concepções, representações e saberes docentes; estabelecem diagnóstico das condições profissionais dos professores; identificam e analisam o perfil sociográfico do professor, sua estrutura intelectual, seu conhecimento "alternativo", suas concepções sobre Ciência, em especial, a Biologia e seus conceitos centrais, métodos de produção científica, educação, ensino-aprendizagem, ambiente, saúde, sexualidade, etc. Descrevem e analisam a prática pedagógica de professores, explicitando suas idiossincrasias e concepções relativas ao processo educacional.

4. Características dos Alunos (CA): traçam o diagnóstico das condições socioeconômicas e culturais dos estudantes e suas implicações no desempenho escolar ou aprendizagem em Ciências/ Biologia. Também trabalham na identificação e análise dos conhecimentos prévios e conhecimentos "alternativos" dos alunos (representações, ideias, noções, percepções etc.) sobre conceitos e processos diversos, de sua estrutura intelectual, modelos de pensamento ou de suas concepções sobre ciência, métodos de produção científica, ambiente, saúde, sexualidade, etc. Estudos das atitudes e características de um aluno ou grupo de alunos no contexto dos processos de ensino-aprendizagem.

5. Formação de Conceitos (FC): dedicados à descrição e análise do desenvolvimento de conceitos científicos no pensamento de alunos e/ou professores, implicando processos de mudança, evolução ou perfil conceitual. Comparação de modelos de pensamento com modelos conceituais presentes na História da Ciência. Estudos sobre a relação entre a estrutura conceitual e/ou representações de estudantes e professores e os processos de ensino-aprendizagem de conceitos científicos em contextos formais ou não-formais de ensino. Relação entre modelos de pensamento de estudantes e sua faixa etária e/ou nível de escolaridade. Incluem a análise de propostas dedicadas a modificar conhecimentos de estudantes/docentes ao longo de um processo didático.

6. História, Filosofia e Sociologia da Ciência (HFSC): centrados em questões particulares ou integradas ao campo da História, Filosofia e/ou Sociologia da Ciência e suas relações com a Educação em Ciências. Destacam-se os estudos sobre Natureza da Ciência, sobre Epistemologia da Ciência ou sobre a Sociologia do Conhecimento Científico. Estudos de revisão bibliográfica em fontes primárias e secundárias que resgatam acontecimentos, fatos, debates, conflitos e circunstâncias da produção científica em determinada época do passado remoto, e as articulações entre eles. Necessariamente, devem explicitar alguma relação com o ensino na área de Ciências/Biologia, como fundamentação de currículos, programas de formação de professores, concepções alternativas dos estudantes e outras implicações para os processos de ensino e aprendizagem. Aspectos relativos à Filosofia e/ ou Epistemologia da Ciência, tais como: concepção de ciência, de cientista, de método científico;

Figura 4. Descrição dos focos temáticos utilizados na classificação das 1000 Dissertações e Teses em Ensino de Biologia (1972-2000) (continua) 
7. Educação em espaços não-formais e divulgação científica (EENF): descrevem aspectos relacionados à história, políticas e práticas de divulgação científica e suas relações com a EC e o Ensino de Biologia; as relações entre comunicação pública da ciência e educação; educação em museus e centros de ciências; feiras e exposições de Ciências. Estudos focalizados também na organização de instituições não escolares ou não formais de ensino, tais como: Organizações Não-Governamentais (ONG); Secretarias de Meio-Ambiente, de Saúde, de Cultura; Museus/Centros de Ciências, Clubes de Ciências, Mostras ou Exposições Científicas. Situam-se também nesta linha programas de ensino com atividades extracurriculares para alunos, efetuados em espaços não-formais de ensino (Museus de Ciências, por exemplo).

8. Recursos Didáticos (RD): avaliam materiais ou recursos didáticos no ensino de Ciências e Biologia, tais como textos de leitura, livros didáticos, materiais de laboratório, modelos anatômicos, filmes, fotografias, computadores, internet e demais recursos digitais, jogos, brinquedos, mapas conceituais, entre outros. Trabalhos que propõem, aplicam e avaliam novos materiais didáticos, kits experimentais, softwares e demais objetos virtuais de aprendizagem ou outros recursos e meios instrucionais em situações de ensino. Trabalhos dedicados à proposição e/ou análise do emprego de tecnologias da informação e comunicação na EC, em particular no ensino de Biologia: desenho e avaliação do uso de recursos e ambientes mediados por tecnologias para o ensino; materiais multimídia e hipermídia; recursos audiovisuais e educação à distância. Por fim, temos também trabalhos que lidam com recursos pedagógicos que podem ser úteis na formação e prática pedagógica dos professores.

9. Educação Ambiental (AMB): focalizam as relações entre Educação Ambiental e Educação em Ciências; educação para o desenvolvimento sustentável; educação para a sustentabilidade. Devem apresentar conexões com questões associadas ao Ensino de Ciências/Biologia.

10. Educação em Saúde (E-S): no contexto do Ensino de Ciências/Biologia são estudos centrados na análise das relações entre Educação e Saúde; educação popular em saúde, promoção da saúde no ambiente das aulas de Ciências e Biologia, formação dos professores para o trabalho com assuntos ligados às questões de saúde, etc.

11. Linguagens e Discurso (L\&D): focalizam a análise de abordagens discursivas, argumentação, interações discursivas, leitura e escrita no ensino de Ciências/Biologia.

12. Alfabetização científica e tecnológica, abordagens CTS e CTSA (CTS): estudo das relações entre ciência, tecnologia e sociedade, envolvendo questões sociocientíficas, temas controversos, letramento científico; aplicações do Movimento CTS (abordagens, enfoques, educação CTS) em contextos de ensino-aprendizagem (recursos didáticos, oficinas, sequências didáticas, unidades de ensino, etc.).

Figura 4. Descrição dos focos temáticos utilizados na classificação das 1000 Dissertações e Teses em Ensino de Biologia (1972-2000) (continua) 
13. Questões curriculares, programas e projetos (CUR): focalizados no desenvolvimento curricular e nas políticas de currículo; conhecimento escolar; história das disciplinas; reformas curriculares, suas implementações e avaliações; inovação educacional; currículo e cultura. Fundamentos para currículo. Estudos dos princípios, parâmetros, diretrizes e fundamentos teórico-metodológicos para o ensino de Ciências/Biologia, contemplando os diversos elementos convencionalmente atribuídos ao desenho curricular: objetivos educacionais, conteúdos, estratégias, avaliação etc. Discussão do papel da escola e da universidade, das relações entre ciência e sociedade, e outros aspectos do sistema educacional. Avaliação de propostas curriculares, reformas curriculares, projetos pedagógicos ou projetos educacionais. Proposição e desenvolvimento de programas/propostas alternativas de ensino para um ano escolar, disciplina, semestre letivo ou ciclo escolar completo. Pesquisas de caráter histórico sobre mudanças curriculares ocorridas de forma global no ensino de Ciências/Biologia, ou sobre modificações a respeito de aspectos mais particulares (materiais didáticos, currículos, legislação, formação de professor, etc.), abrangendo determinada época do passado próximo ou remoto.

14. Avaliação (AVA): preocupam-se com aspectos teóricos e metodológicos da avaliação; abordagens e práticas de avaliação em programas e processos de ensino-aprendizagem; indicadores de desempenho e avaliação; avaliação de sistemas; estudos comparativos internacionais.

15. Diversidade e educação inclusiva (D\&I): relações entre ensino de Ciências/Biologia e temas tais como inclusão, gênero, raça, etnia, classe, educação indígena e de demais grupos sociais específicos, políticas de ações afirmativas etc.

16. Pesquisa e produção científica (PPC): considerações epistemológicas sobre a natureza da pesquisa; referenciais teóricos da pesquisa em EC; EC como campo científico; reflexões acerca de metodologias e métodos de pesquisa, estudos do tipo estado da arte e outras modalidades de estudos de levantamento e análise da produção acadêmica e científica na área.

17. Organização do espaço escolar (OEE): diagnóstico das características de instituições escolares da educação básica ou superior, abrangendo questões e situações relativas à gestão escolar nos seus aspectos político-administrativo, pedagógico, funcional, físico, entre outros. Pesquisas que analisam como a escola e a comunidade escolar se organizam para receber propostas inovadoras e/ou modificar estruturas de ensino-aprendizagem tradicionais, considerando o ensino de Ciências/Biologia. Estudos focalizando as relações entre os diversos segmentos escolares e da escola com a comunidade.

Figura 4. Descrição dos focos temáticos utilizados na classificação das 1000 Dissertações e Teses em Ensino de Biologia (1972-2000)

Fonte: Adaptação (Teixeira, 2008; Megid Neto, 1999; 10 ENPEC).

Na sequência, a Figura 5 traz a distribuição das 1000 DTs conforme a classificação realizada para focos temáticos. Além disso, esses trabalhos são apresentados conforme sua distribuição por décadas.

Com a observação do gráfico, verificamos a existência de seis focos de maior incidência de produção, isto é, áreas temáticas as quais a maior parte dos trabalhos está concentrada ao longo dos 40 anos investigados. São elas: Ensino-Aprendizagem (19,6\%), Recursos Didáticos (16,2\%); Características dos Professores (11,9\%); Formação de Professores (11\%); Características dos Alunos (10,7\%); e Questões Curriculares, Programas e Projetos (9,7\%). Essas seis áreas temáticas aglutinam praticamente $80 \%$ da produção investigada. Assim, parece razoável argumentar que os pesquisadores selecionam como problemas prioritários, temáticas ligadas às seis linhas acima mencionadas. 


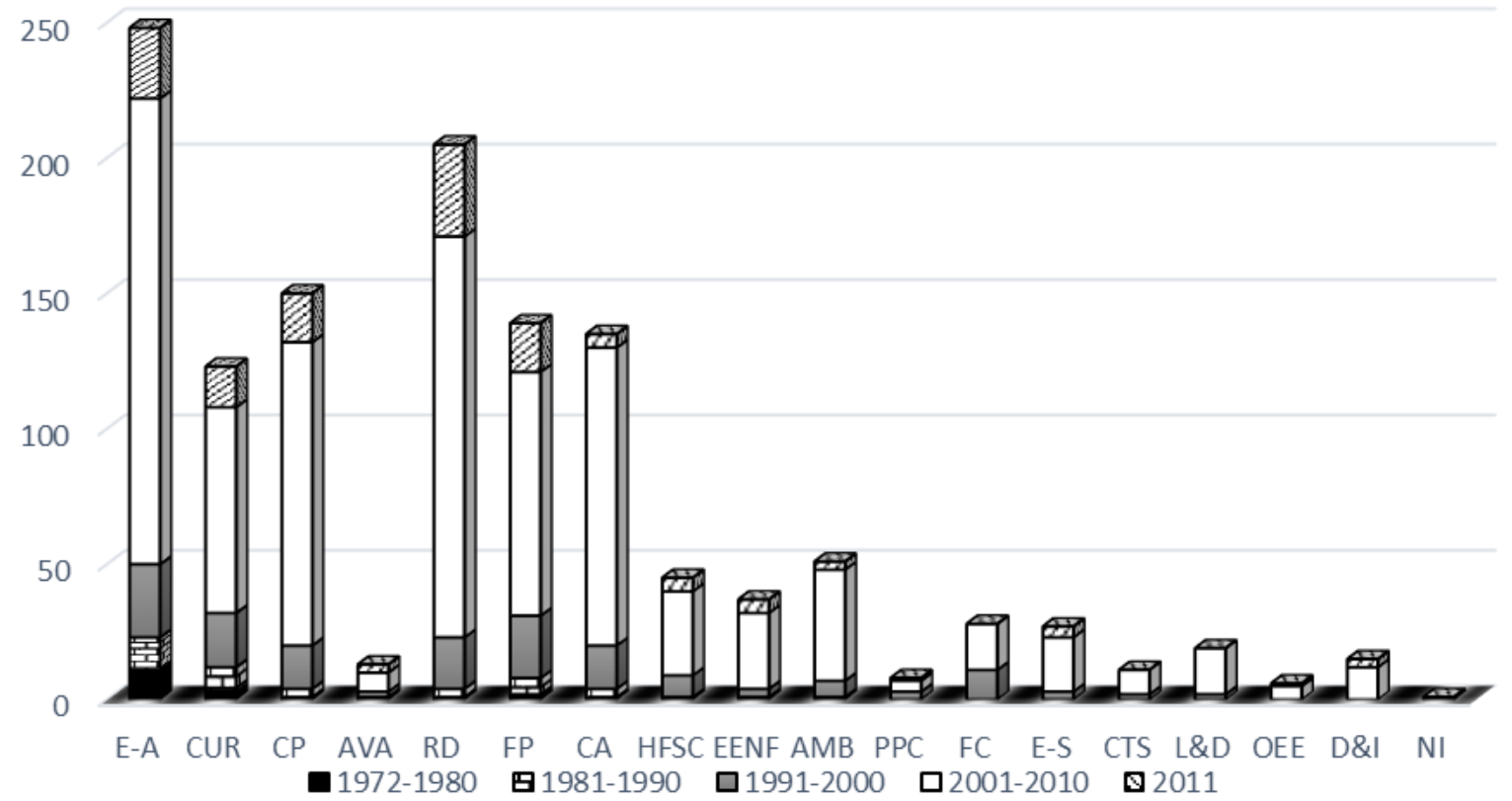

Figura 5. Gráfico da distribuição das DTs em Ensino de Biologia conforme focos temáticos ao longo das quatro décadas examinadas na pesquisa (1972-2011)

Fonte: elaborado pelos autores.

Legenda: EA: Ensino-Aprendizagem; CUR: Questões Curriculares, Programas e Projetos; CP: Características dos Professores; AVA: Avaliação; RD: Recursos Didáticos; FP: Formação de Professores; CA: Características dos Alunos; HFSC: História, Filosofia, Sociologia da Ciência; EENF: Educação em Espaços não Escolarizados; AMB: Educação Ambiental; PPC: Pesquisa e Produção Científica; FC: Formação de Conceitos; E-S: Educação em Saúde; L\&D: Linguagem e Discurso; OEE: Organização do Espaço Escolar; D\&I: Diversidade e Educação Inclusiva; NI: Foco Temático não-identificado.

Porém, o comparativo dos dados agora explicitados com aqueles encontrados em outros estudos apresentados anteriormente (Teixeira, 2008; Teixeira \& Megid Neto, 2012; Teixeira, 2012) torna possível salientar alguns aspectos interessantes. Para isso, é útil a visualização dos dados da Figura 5, examinados em conjunto com os dados complementares explicitados na Tabela 4.

Tabela 4. Evolução dos percentuais de trabalhos nas seis linhas temáticas principais da produção acadêmica em Ensino de Biologia (1972-2011)

\begin{tabular}{lccc}
\hline Focos Temáticos & $1972-2004$ & $1972-2006$ & $1972-2011$ \\
\hline Ensino-Aprendizagem & $18,4 \%$ & $21,1 \%$ & $19,6 \%$ \\
Recursos Didáticos & $12,0 \%$ & $15,6 \%$ & $16,2 \%$ \\
Características dos Professores & $14,2 \%$ & $14,3 \%$ & $11,9 \%$ \\
Formação de Professores & $17,1 \%$ & $16,0 \%$ & $11,0 \%$ \\
Características dos Alunos & $13,0 \%$ & $14,1 \%$ & $10,7 \%$ \\
Questões Curriculares & $14,2 \%$ & $12,9 \%$ & $9,7 \%$ \\
\hline Totalização & $88,9 \%$ & $94,0 \%$ & $79,1 \%$ \\
\hline
\end{tabular}

Fonte: elaborado pelos autores. 
O primeiro destaque refere-se à queda do percentual conjunto dessas seis categorias no último quinquênio. Se antes essas seis linhas concentravam de 89 a 94\% da produção acadêmica, agora, representam algo próximo a 79\% (Tabela 4);

Outro ponto está relacionado ao aumento dos trabalhos dedicados a "Recursos Didáticos", conforme mostra a Tabela 4, o único dos seis focos principais que teve seu percentual aumentado no período 2006-2011.

A Figura 5 evidencia claramente linhas consolidadas de investigação que são objeto de atenção desde os primeiros momentos e vêm se mantendo no intervalo de tempo sob análise (E-A; CUR; FP; CP; CA; RD), convivendo com linhas que emergiram mais tarde e vêm se fortalecendo (HFSC; AVA; EENF; AMB; E-S), além de áreas relativamente recentes que passam a chamar significativa atenção dos autores (CTS; L\&D; PPC; D\&I). Por fim, temos linhas que recebem atualmente pouco interesse dos investigadores (OEE; FC).

Entre os poucos estudos sobre pesquisa e produção científica, incluindo aqueles voltados para discussão de questões teóricas e metodológicas, predominam trabalhos de levantamento de estudos na área, os chamados Estado da Arte. O percentual de estudos dedicados à análise da organização dos espaços escolares (OEE) relacionadas ao Ensino de Biologia, indica que essa é uma área de silêncio na produção investigada. Além disso, trabalhos que focalizam problemáticas relacionadas às políticas públicas (educacionais), foco que aparece em outros estudos de estado da arte, não apareceram no conjunto da produção aqui investigada.

Voltando à Tabela 4, a queda no percentual conjunto dos seis focos temáticos principais é, a nosso ver, reflexo da diversificação das temáticas de estudo na área. Com efeito, nos últimos 10 anos, ganharam destaque progressivo diversas linhas de investigação que antes não reuniam número significativo de trabalhos. Entre elas destacamos: História e Filosofia da Ciência, Educação em Espaços não Formais, Educação Ambiental, Educação em Saúde, Linguagem e Discurso, Abordagens CTS, e, Diversidade e Inclusão. A emergência dessas linhas de investigação, algumas mais antigas, outras mais recentes, é reflexo do movimento da área de Educação em Ciências, ao expandir e pluralizar sua agenda de interesse, atingindo outros horizontes, para além das temáticas tradicionais de pesquisa caracterizadoras da área nas décadas de 1980/1990.

O aumento de estudos dedicados ao foco temático "recursos didáticos", é, a nosso ver, fenômeno associado, em primeiro lugar, ao pragmatismo que caracteriza parte significativa dos estudos acadêmicos nas áreas de Educação e Educação em Ciências (Mortimer, 2002; Miranda \& Resende, 2006). Esse fenômeno se expressa também quando observamos que os dois focos temáticos com número mais expressivo de DTs identificadas são justamente "Ensino e Aprendizagem" e "Recursos Didáticos" (Figura 5). Também se associam às informações já explicitadas, a emergência e o crescimento dos mestrados profissionais, que se caracterizam igualmente por uma ênfase mais centrada no desenvolvimento de processos de ensino-aprendizagem e de recursos e materiais didáticos associados. Das 99 DTs identificadas nos MP, 31 foram classificadas 
no referido foco temático, com trabalhos voltados para livros didáticos, paradidáticos, textos de divulgação científica, cartilhas, modelos, jogos didáticos, uso de imagens, filmes, vídeos, CDs/DVDs, recursos informáticos e novas tecnologias (blogs, ambientes virtuais de aprendizagem, animações, etc.). Ademais, os focos temáticos E-A e RD somam $75 \%$ das DTs oriundas de MP. Também notamos que 79\% desses estudos estão vinculados a problemáticas relacionadas à educação básica, com destaque para o ensino médio (60 DTs) e Ensino Fundamental - anos finais (20 DTs).

Portanto, essas informações dão sustentação a outro aspecto que vale destacar quando examinamos as problemáticas investigadas no conjunto da produção acadêmica analisada, isto é, "a grande preocupação dos autores com a repercussão de suas pesquisas na sala de aula". Como anteriormente afirmado (Teixeira, 2008), é visível a preocupação com a aplicabilidade dos resultados de pesquisa na realidade escolar, fato já observado também em outros trabalhos identificados na literatura (Mortimer, 2002; Salem, 2012). Salem (2012), por exemplo, aponta que uma das marcas características das pesquisas em EC, "presente em seu DNA", como diz a autora, é a preocupação com os processos de Ensino-Aprendizagem e as múltiplas variáveis que interferem neste contexto. Em particular, o referido trabalho confirma essa tendência para as pesquisas em Ensino de Física. A situação é análoga para as pesquisas em Ensino de Biologia, dado sustentado seja pela identificação de grande quantidade de DTs classificadas nos focos temáticos E-A e $\mathrm{RD}$, seja pela boa quantidade de trabalhos preocupados com as práticas pedagógicas (características dos professores), com a formação docente (formação de professores), com aspectos relacionados ao desenrolar do currículo nas salas de aula (questões curriculares) e também aquelas focalizadas em aspectos associados aos estudantes (características dos alunos). Assim, este trabalho, de certa forma, corrobora a ideia formulada em outros estudos, no sentido de apontar que uma das motivações para a pesquisa na área está associada a "uma demanda pelo aprimoramento do aprendizado do conhecimento científico" (Salem, 2012, p. 21).

Ainda em relação às linhas temáticas e problemas de estudo gostaríamos de destacar os seguintes aspectos:

- No intervalo de tempo examinado, entre os seis focos principais, os estudos dedicados à Formação de Professores, são aqueles que mais perdem espaço (Tabela 4: de 17\% para 16\%; depois, de $16 \%$ para $11 \%$ ). Em seu conjunto, esses estudos priorizam a dimensão da formação inicial; o número de estudos dedicados à formação continuada não ultrapassa $20 \%$ do total de DTs classificadas na linha temática "Formação de Professores";

- Formação Conceitual parece ser uma linha temática que aglutina número cada vez menor de trabalhos, sobretudo se tomarmos os estudos iniciais da área de EC, voltados para identificação das concepções alternativas dos alunos e para a ideia de problematizá-las e/ou reestruturálas no sentido de aproximá-las do conhecimento científico. Atualmente, os poucos estudos dentro deste foco temático têm se preocupado com questões que, por vezes, escapam da esfera estritamente conceitual, envolvendo aspectos relativos a concepções pedagógicas, filosóficas e epistemológicas. Aliás, essa tendência foi também observada por Lee, Wu e Tsai 
(2009), ao examinarem artigos publicados nos três periódicos mais influentes da área de Educação em Ciências no mundo, no período 2003-2007. Eles detectaram mudança nos tópicos de pesquisa de mais interesse entre os pesquisadores: se antes apareciam em destaque os estudos sobre aprendizagem e mudança conceitual, no referido período ganham destaque, segundo os autores, os estudos envolvendo os contextos de aprendizagem dos estudantes.

- Nas questões curriculares associadas a aspectos da formação de professores faltam estudos acadêmicos dedicados a examinar o impacto das políticas curriculares nos cursos de licenciatura. Pouco sabemos sobre o impacto dessas normatizações e, em específico, sobre as diretrizes curriculares para formação de professores e suas reformulações mais recentes nos currículos dos cursos de licenciatura e na prática de ensino. Ainda em relação aos estudos curriculares, destacamos o reduzido número de DTs ligadas aos enfoques CTS: apenas 11 DTs, das quais, pequeno número busca aplicar e testar, via pesquisa de intervenção, propostas CTS para contextos do ensino-aprendizagem de Biologia.

- Os professores ainda são objeto de forte interesse, seja na linha dedicada à Formação de Professores, seja no foco "Características dos Professores". Praticamente 23\% das DTs estão inseridas nessas duas linhas temáticas. Porém, quando observamos as pesquisas de natureza interventiva, são raríssimos os estudos que trabalham em contextos de parceria com os professores da educação básica. Neste sentido, eles são mais objetos do que sujeitos ativos nos estudos que realizamos.

- Quanto às caraterísticas dos professores, as DTs focalizam, em sua maior parte, os docentes da educação básica. O professor da universidade, e, mais especificamente, o professor formador no contexto dos cursos de licenciatura, exceto aqueles envolvidos diretamente na Prática de Ensino e Estágio Supervisionado, raramente são estudados ou participam de projetos de investigação.

\section{Gêneros de Trabalho Acadêmico e Tendências Metodológicas}

Neste caso, desenvolvemos um processo de análise inspirado no trabalho de Soares e Maciel (2000), o que nos permitiu o estabelecimento de uma classificação sobre a natureza de cada trabalho. Com efeito, classificamos um determinado documento como ensaio e/ou estudo de natureza teórica (ENS) quando houve ausência de trabalho com dados empíricos e/ou pela apresentação de ensaios propondo reflexões sobre pressupostos, temáticas e referências teóricas de interesse para o Ensino de Ciências/Biologia. Os relatos de experiência (RE) caracterizam-se pela descrição e análise de uma prática e/ ou experiência promovida e efetivada pelo próprio autor do trabalho. Distinguem-se da pesquisa genérica e vagamente denominada de "pesquisa-ação" porque, nesta, aquele que desenvolve a experiência se faz intencionalmente pesquisador, dirigindo sua ação segundo o fenômeno que pretende investigar; enquanto que no relato de experiência é desenrolada a uma descrição e análise de uma experiência desenvolvida sem a intenção inicial de realizar um tratamento sistemático e metodologicamente rigoroso de um problema configurado pelo pesquisador ou pesquisadores (Megid Neto, 1999; Soares \& Maciel, 2000). Os estudos empírico-descritivos (PD) caracterizam-se pela realização de 
pesquisa, com a efetiva coleta de dados, voltada para identificar, diagnosticar, descrever, caracterizar a existência de um fenômeno, buscando formas para explicar os fenômenos examinados, "descobrindo relações, ainda que de caráter tendencial e probabilístico, de natureza causal, funcional ou estrutural". Segundo as autoras, "identificar, descrever e explicar são momentos de uma escala contínua; o pesquisador pode ficar só no primeiro momento, ou pode chegar ao segundo, ou pode ir até o último nível de interpretação, que é a explicação" (p. 59). Outra característica dos estudos deste tipo é a ausência de intervenções envolvendo o objeto de estudo focalizado.

Dissertações e teses caracterizadas como pesquisas de natureza interventiva (PNI) são demarcadas pela realização de uma pesquisa conjugada com ação ou pela implementação de propostas de intervenção voltadas para diversos aspectos referentes ao Ensino de Biologia (pesquisa-ação, investigação-ação, pesquisa participante, pesquisa experimental etc.). Incluímos também junto às PNI os trabalhos caracterizados pelo que podemos chamar de "pesquisa \& desenvolvimento", isto é, marcados pelo "desenvolvimento e testagem de novos processos ou produtos (projetos, manuais, textos, materiais didáticos, metodologias etc.) [...], esse tipo de pesquisa parte de um problema identificado, geralmente de natureza mais prática e cuja tentativa de solução se faz imediata; o pesquisador [...] lança-se ao desenvolvimento de um determinado produto ou processo que viabilize a solução do problema [...]" (Megid Neto, 2014, p. 108). Além do desenvolvimento do material ou processo, por vezes temos a descrição de situações de testagem de sua utilização, embora essa não seja condição obrigatória.

Finalmente, temos também um grupo de trabalhos enquadrados como "mais de uma pesquisa" (MDP). Nestes poucos casos, se combinam diferentes situações (PD+RE; PD+PNI; ENS+PD; P\&D+PNI). A Figura 6 traz a distribuição das 1000 DTs em percentuais conforme a categorização para gêneros de trabalho acadêmico.

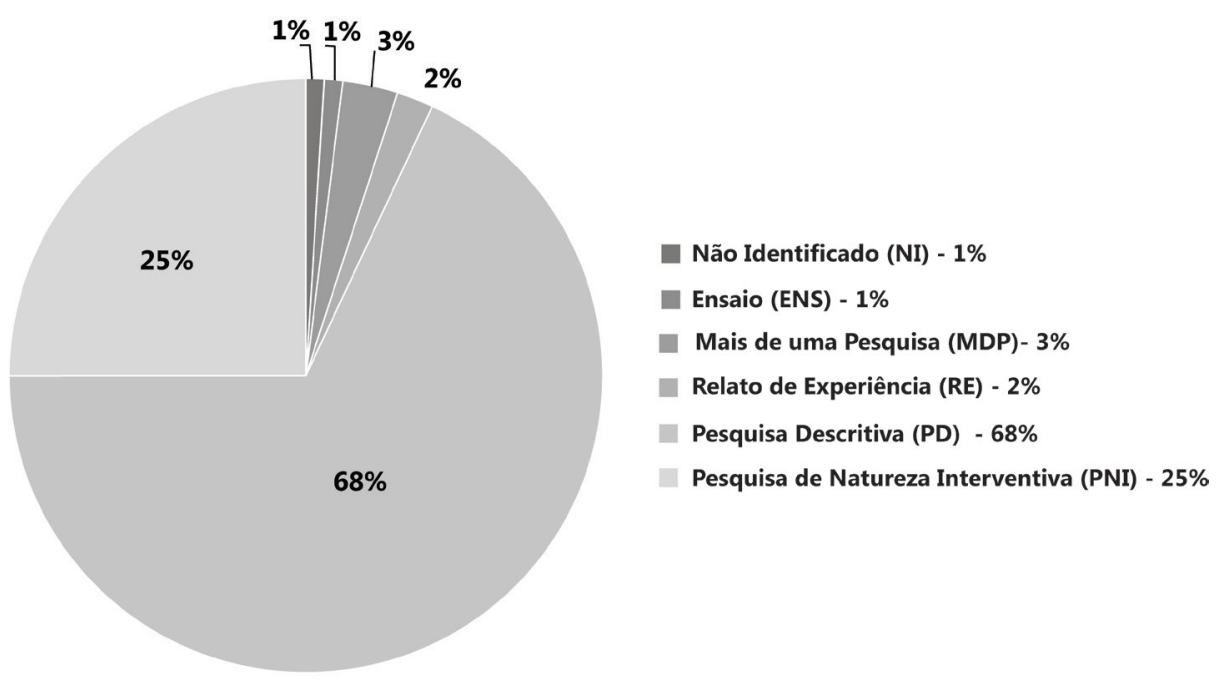

Figura 6. Percentuais relativos a cada um dos gêneros de trabalho acadêmico.

Fonte: elaborado pelos autores. 
Neste quesito o primeiro ponto a destacar refere-se à primazia dos estudos do tipo "pesquisa" sobre outras modalidades, como os relatos de experiência e ensaios teóricos. Detectamos que $96 \%$ das DTs examinadas desenvolvem trabalhos do tipo pesquisa. Os ensaios teóricos são raros. Nem mesmo entre as Teses de Doutorado as pesquisas de natureza teórica ganham mais intensidade. Nosso argumento, ao verificar esses dados, é que essa modalidade de estudos acadêmicos poderia ser explorada de forma mais sistemática. Entendemos que estudos dessa natureza seriam úteis para examinar em profundidade temas de grande interesse para a área, como as questões curriculares e o ensino de Biologia, as políticas públicas para a área, a questão da interdisciplinaridade e da contextualização e a Educação CTS, conceitos estruturantes para as Ciências Biológicas e o Ensino de Biologia, questões históricas, filosóficas e epistemológicas, nossas pesquisas e problemas teórico-metodológicos, etc.

Entre as pesquisas, há prevalência de trabalhos pautados metodologicamente pelas abordagens qualitativas de investigação educacional. As abordagens predominantemente quantitativas, de inclinação positivista ou pós-positivista, ainda se fazem presentes, mas, em número reduzido de trabalhos. De qualquer forma, nos capítulos dedicados ao detalhamento dos procedimentos metodológicos, as discussões sobre os paradigmas que envolvem a pesquisa educacional e seu impacto em nossas práticas de investigação estão praticamente ausentes e/ou silenciadas (Alves-Mazzotti \& Gewandsznajder, 2004).

Há predomínio dos estudos empírico-descritivos (68\%), sobretudo aqueles centrados em alguma forma de "análise de conteúdo" de entrevistas, questionários, documentos, materiais didáticos, textos de divulgação científica etc. Os estudos etnográficos e mesmo os chamados "estudos de caso" ${ }^{12}$ são raros, se considerarmos os critérios consagrados pela literatura para caracterizá-los.

As pesquisas de natureza interventiva totalizam 25\% dos trabalhos analisados na investigação, o que significa que, neste conjunto de 1000 DTs em Ensino de Biologia, a cada quatro estudos, um se caracteriza por assumir natureza interventiva. Seria um bom número? A propósito, em estudo em fase avançada de desenvolvimento, serão oferecidas informações detalhadas sobre as PNI produzidas nos trabalhos dedicados ao Ensino de Biologia. Nele uma análise sobre este grupo específico de trabalhos foi realizada como parte do projeto de pós-doutoramento do primeiro autor deste artigo.

\section{Considerações Finais}

Gostaríamos de finalizar este artigo destacando o desenvolvimento de nossa área de estudos e pesquisas. Como mostramos, a expansão e a diversificação da pós-graduação

12 Estudo de Caso é modalidade de pesquisa que exige pelo menos quatro quesitos: i) singularidade, isto é, caracteriza-se pela pesquisa de situações particulares, distintas das usuais, o que justifica o interesse por investigálas. Segundo André e Lüdke (2013), o caso é "uma representação singular da realidade que é multidimensional e historicamente situada" (p. 24); ii) examinam situações em realidade natural, isto é, são estudos naturalísticos; iii) exigem forte imersão do pesquisador no contexto estudado, implicando no tempo que ele passa para acompanhar, descrever e analisar o fenômeno estudado; iv) utilização de múltiplos instrumentos de coleta de dados, para garantir uma interpretação em contexto e sob várias perspectivas, o que ajuda também na construção de uma descrição mais aprofundada do caso. 
na subárea de Ensino de Biologia é significativa; é um dado de nossa realidade que precisa ser valorizado. Neste processo, papel interessante têm os mestrados profissionais da área de Ensino da CAPES que, no quadro atual, vão potencializar a produção acadêmica, atuando como vetores que aumentarão sensivelmente a produção na área. Entretanto, ainda temos poucas informações sobre esses trabalhos. Por isso, é imprescindível a realização de estudos de Estado da Arte que focalizem exatamente essa modalidade de dissertações.

Outro ponto a ser enaltecido é o aumento paulatino da representatividade das regiões nordeste, norte e centro-oeste, o que indica que estamos avançando no processo de redução das assimetrias regionais na distribuição de programas da área pelas várias regiões brasileiras. Este é um processo que as políticas públicas, particularmente aquelas impulsionadas pela CAPES precisam manter e, se possível, intensificar.

Seria muito interessante também ampliar os estudos voltados para os contextos da educação infantil, da educação fundamental, sobretudo nos anos iniciais, e também da EJA. Como observamos na análise de dados, esses são segmentos de escolarização que continuam recebendo diminuta atenção nos estudos sobre o Ensino de Biologia.

Em linhas gerais, o conjunto de DTs em Ensino de Biologia produzidas ao longo desses 40 anos, mostra a diversidade temática e metodológica dessa subárea. Vislumbramos um processo de busca de equilíbrio entre as pesquisas de natureza mais compreensiva e aquelas marcadas por algum tipo de natureza interventiva. Esse é outro dos grandes atributos de nossa área, ou seja, desenvolvemos pesquisas empíricodescritivas e produzimos conhecimentos articulados com a pesquisa aplicada e o desenvolvimento de produtos e processos educacionais, tudo isso, com potencial de aplicação em condições reais de ensino e aprendizagem.

Quando assinalamos, na seção de introdução do artigo, que nossa área atingiu a maturidade, pensamos esse conceito principalmente em termos institucionais. Todavia, é preciso observar agora, com mais atenção, outra gama de questões e problemas. É preciso disposição para enfrentarmos temáticas complexas e de difícil equalização. Por exemplo: sobre a qualidade das pesquisas produzidas na área e o problema do aprimoramento teórico-metodológico; sobre o alcance de nossos estudos, em termos de produção de conhecimentos e de geração de mudanças nas práticas, seja no campo dos processos de ensino-aprendizagem, seja nos processos ligados à formação de professores; a questão da comunicação entre o que estamos produzindo junto aos demais agentes que atuam na escola básica; a questão do estabelecimento de parcerias para viabilização de pesquisas que envolvam mais intensamente os professores da educação básica e as condições necessárias para isso; e, finalmente, sobre as relações que estabelecemos com os formadores de opinião pública e, principalmente, com os tomadores de decisão na esfera das políticas públicas em educação/educação científica.

Os dados aqui divulgados permitem uma série de reflexões e inúmeras considerações, dependendo do foco de interesse do leitor. De qualquer forma, entendemos que a apresentação das informações e reflexões explicitadas no artigo contribui para o 
avanço de nossa compreensão sobre o desenvolvimento dessa subárea de pesquisa no país, abrindo espaço para a realização de estudos analíticos concentrados em aspectos específicos relativos a produção inventariada.

\section{Agradecimentos}

À Faculdade de Educação da Universidade Estadual de Campinas (UNICAMP), nossa "casa" durante o estágio de pós-doutoramento. Financiadores: FAPESB, Edital n. 019/2010; CNPQ, Edital Universal 14/2011; PPG/UESB Edital 61/2013; CAPES/ FAPESB/PPG UESB - Bolsa de Pós-Doutoramento.

\section{Referências}

Alves-Mazzotti, A. J., \& Gewandsznajder, F. (2004). O método nas ciências naturais e sociais: pesquisa quantitativa e qualitativa. São Paulo: Pioneira T. Learning.

Barros, S. S. (2002). Reflexões sobre 30 anos da pesquisa em Ensino de Física. In Anais do $8^{\circ}$ Encontro Nacional de Ensino de Física, SBF: Águas de Lindóia, SP.

Campos, M. M., \& Fávero, O. (1994). A pesquisa em educação no Brasil. Cadernos de Pesquisa, 88, 5-17.

Chisté, P. S. (2016). Pesquisa-Ação em mestrados profissionais: análise de pesquisas de um programa de pós-graduação em ensino de ciências e de matemática. Ciência \& Educação, 22(3), 789-808.

Gatti, B. A. (1983). Pós-Graduação e pesquisa em Educação no Brasil, 1978-1981. Cadernos de Pesquisa, 44, 3-17.

Goergen, P. (1998). Apresentação. In S. Sánches Gamboa (Org.), Epistemologia da pesquisa em educação (pp. 4-7). Campinas/SP: Práxis.

Krasilchik, M. (1986). Perspectivas do ensino de Biologia. In Coletânea do $2^{\circ}$ Encontro Perspectivas do Ensino de Biologia (pp. 5-14). São Paulo, SP, Faculdade de Educação (USP).

Krasilchik, M. (2004). Prática de Ensino de Biologia. São Paulo: Edusp.

Kuenzer, A. Z., \& Moraes, M. C. M. (2005). Temas e tramas na pós-graduação em Educação. Educação \& Sociedade, 26(93), 1341-1362.

Lee, M-H., \& WU, Y-T; Tsai, C-C. (2009). Research trends in Science Education from 2003 to 2007: a content analysis of publications in selected journals. International Journal of Science Education, 31(15), 1999-2020.

Lemgruber, M. S. (1999). A educação em ciências físicas e biológicas a partir das teses e dissertações (1981 a 1995): uma história de sua história. (Tese de Doutorado em Educação), Universidade Federal do Rio de Janeiro, Rio de Janeiro. 
Lüdke, M. (2006). A pesquisa em educação ao encontro de sua complexidade. In A. M. M. S. Silva (Orgs.), Educação formal e não formal, processos formativos e saberes pedagógicos: desafios para a inclusão social (pp. 413-424). Recife: ENDIPE.

Macedo, E., \& Sousa, C. P. (2010). A pesquisa em educação no Brasil. Revista Brasileira de Educação, 15(43), 166-176.

Megid Neto, J. (1999). Tendências da pesquisa acadêmica sobre o ensino de ciências no nível fundamental. (Tese de Doutorado em Educação). Universidade Estadual de Campinas, Campinas/SP.

Megid Neto, J. (2007). Três décadas de pesquisas em Educação em Ciências: tendências de teses e dissertações (1972-2003). In R. Nardi (Org.), A pesquisa em ensino de Ciências no Brasil: alguns recortes (pp. 341-355). São Paulo: Escrituras.

Megid Neto, J. (2014). Origens e desenvolvimento do campo de pesquisa em Educação em Ciências no Brasil. In: R. Nardi, \& T. V. O. Gonçalves. A pós-graduação em Ensino de Ciências e Matemática no Brasil: memórias, programas e consolidação da pesquisa na área (pp. 98-139). São Paulo: ELF.

Miranda; M. G., \& Resende, A. C. A. (2006). Revista Brasileira de Educação, 11(33), 511-518.

Moreira, M. A. A. (2004). Pós-graduação e pesquisa em ensino de Ciências no Brasil. In Atas do $4^{\circ}$ Encontro Nacional de Pesquisa em Educação em Ciências, Porto Alegre: ABRAPEC.

Mortimer, E. F. (2002). Uma agenda para a pesquisa em Educação em Ciências. Revista Brasileira de Pesquisa em Educação em Ciências, 2(1), 25-35.

Nardi, R. (2007). A área de ensino de Ciências no Brasil: fatores que determinaram sua constituição e suas características segundo pesquisadores brasileiros. In R. Nardi (Org.). A pesquisa em ensino de Ciências no Brasil: alguns recortes (pp. 357-412). São Paulo: Escrituras.

Salem, S. (2012). Perfil, evolução e perspectivas da pesquisa em Ensino de Física no Brasil. (Tese de Doutorado em Ensino de Ciências). Universidade de São Paulo, São Paulo.

Scarpa, D. L., \& Silva, M. B. (2013). A Biologia e o ensino de Ciências por investigação: dificuldades e possibilidades. In A. M. P. Carvalho. (Org.). Ensino de ciências por investigação: condições para implementação em sala de aula (pp. 129-152). São Paulo: Cengage Learning.

Selles, S. E., \& Ferreira, M. S. (2005). Disciplina escolar Biologia: entre a retórica unificadora e as questões sociais. In M. Marandino, S. E. Selles, M. S. Ferreira, \& A. C. Amorim (Orgs.). Ensino de Biologia: conhecimentos e valores em disputa (pp. 50-62). Niterói: Eduff.

Soares, M. B., \& Maciel, F. (2000). Alfabetização. Brasília: MEC/INEP/COMPED. 
Teixeira, P. M. M. (2008). Pesquisa em Ensino de Biologia no Brasil (1972-2004): um estudo baseado em dissertações e teses. (Tese e Doutorado em Educação). Universidade Estadual de Campinas, Campinas/SP.

Teixeira, P. M. M. (2012). 35 anos da produção acadêmica em Ensino de Biologia no Brasil: catálogo analítico de dissertações e teses (1972-2006). V. Conquista: Ed. UESB.

Teixeira, P. M. M., \& Megid Neto, J. (2006). Investigando a pesquisa educacional. Um estudo enfocando dissertações e teses sobre o ensino de Biologia no Brasil. Investigações em Ensino de Ciências, 11(2), 261-282.

Teixeira, P. M. M., \& Megid Neto, J. (2011). Pós-Graduação e pesquisa em ensino de Biologia no Brasil: um estudo baseado em dissertações e teses. Ciência \& Educação, 17(3), 559-578.

Teixeira, P. M. M., \& Megid Neto, J. (2012). O estado da arte da pesquisa em ensino de Biologia no Brasil: um panorama baseado na análise de dissertações e teses. Revista Electrónica de Enseñanza de las Ciencias, 11(2), 273-297.

Teixeira, P. M. M., \& Oliveira, F. S. (2013). 40 anos de pesquisa em Ensino de Biologia no Brasil: um estudo baseado em dissertações e teses (1972-2011). In Atas do $9^{\circ}$ Encontro Nacional de Pesquisa em Educação em Ciências. Águas de Lindóia: ABRAPEC.

Teixeira, P. M. M., Silva, M. G.; \& Anjos, M. S. (2009). 35 anos da pesquisa em Ensino de Biologia no Brasil: um estudo baseado em dissertações e teses (1972-2006). In Atas do $7^{\circ}$ Encontro Nacional de Pesquisa em Educação em Ciências. Florianópolis/SC: ABRAPEC.

Paulo Marcelo Marini Teixeira

${ }^{\circ}$ http://orcid.org/0000-0001-9359-7763 Universidade Estadual do Sudoeste da Bahia Departamento de Ciências Biológicas Pós-Graduação em Educação Científica e Formação de Professores Jequié, Brasil paulommt@hotmail.com

Jorge Megid Neto

Universidade Estadual de Campinas

Faculdade de Educação Campinas, Brasil jmegid@gmail.com

Submetido em 05 de Setembro 2016 Aceito em 15 de Abril 2017

Publicado em 31 de Agosto de 2017 